\section{Compression fractures of the dorsal spine in hypoglycaemic fits in diabetes}

Compression fractures of the bodies of the mid-dorsal vertebrae have been described in tetanus, ${ }^{1}$ in convulsion therapy for mental illness, ${ }^{2.3}$ and in idiopathic epilepsy. ${ }^{+}$So far as I know they have never been reported after hypoglycaemic attacks in insulin treated diabetes. I have seen four such cases in the past eight years, in one of which the diagnosis was not at first recognised.

\section{Case reports}

Case 1-A man aged 48 had been diabetic since the age of 17 and was receiving a single injection of semilente and lente insulin. He had a nocturnal fit in which he bit his tongue and had pain in the upper part of his back. He came to hospital the next day, and $x$ ray pictures showed a compression fracture of the bodies of T3 and $\mathrm{T} 4$ (figure).

\section{Comment}

All four men made rapid recoveries and were left with minimal deformity and little disability. In convulsions the fractures usually affect one or two of the third to eighth dorsal vertebrae, are usually associated with attacks during sleep, and are more common in men. Roberg studied the mechanics of these "flexion fractures" and why they occurred in the dorsal region. $\mathrm{He}$ suggested that they were to do with the strength of the spinal extensors in the dorsal region being less than in the cervical and lumbar spine and with the strength and mechanical advantage of the flexors working from the pelvis to the rib cage.' The limited mobility of the dorsal spine explains the rapid recovery and limited disability.

The other puzzle is why, having been treating diabetics for more than 30 years, it is only in the past eight years that these cases have come to my notice. It seems unlikely that they occurred as frequently in the past but were unrecognised. Recent factors may be the increasing use of twice daily insulin injections and the greater emphasis on good control to avoid complications.

If a diabetic patient (particularly a young man) complains of back pain after a severe hypoglycaemic attack-especially a nocturnal attack-an $x$ ray picture should be taken. If a compression fracture is found conservative treatment will be followed by rapid recovery.

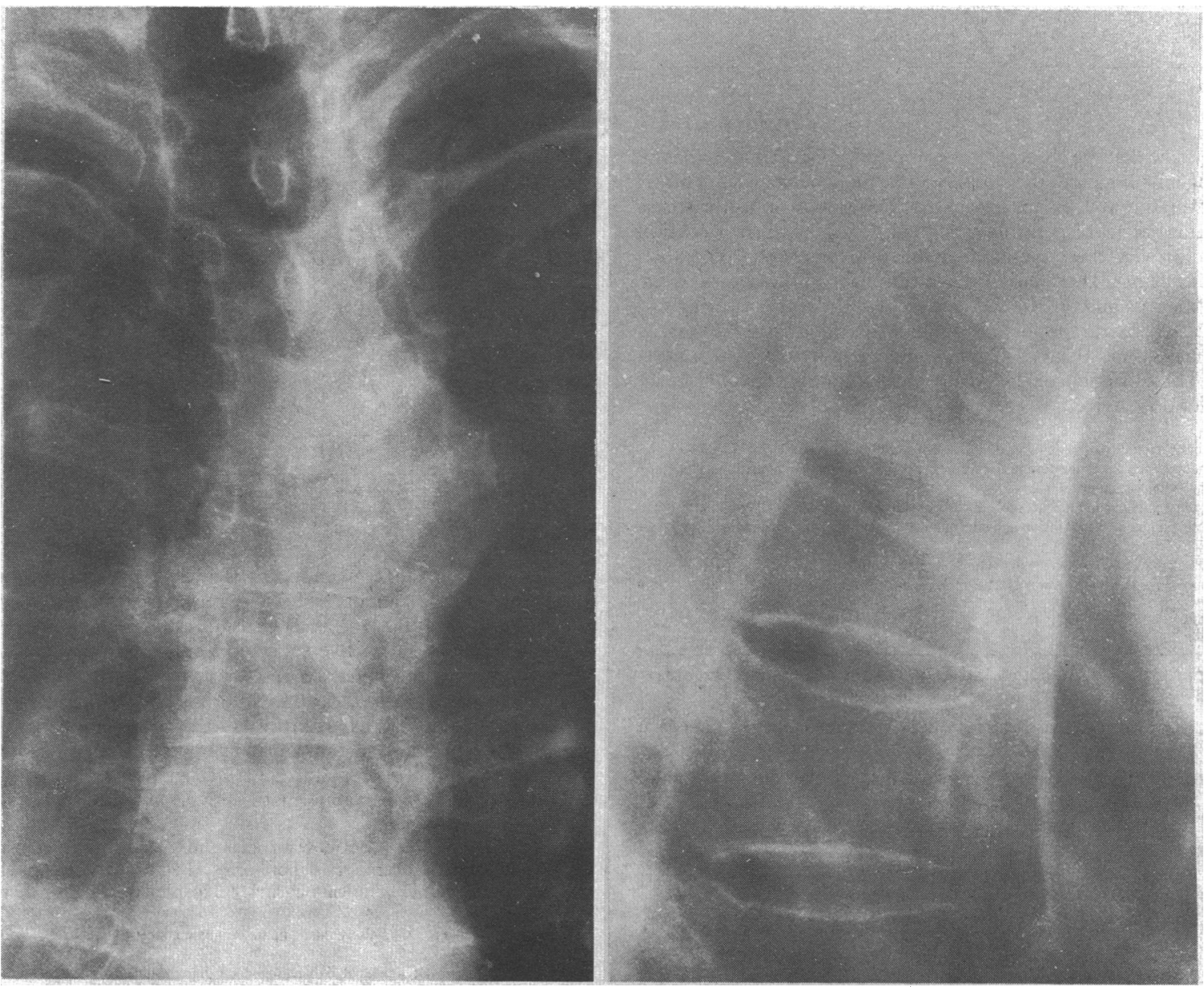

Case 1. Posteroanterior (left) and lateral (right) radiographs of dorsal spine showing compression fractures of T3 and T4.

Case 2-A 30 year old man with a history of diabetes for two years and taking soluble and isophane insulin twice a day awoke at 530 am with severe pain in the upper back. He was brought to hospital as an emergency case and admitted to the orthopaedic ward with an unexplained compression fracture of T5 and T6.

Case 3-A man of 35 had been diabetic for 22 years and was taking soluble and isophane insulin in the morning and soluble and ultralente insulin in the evening. He had a severe hypoglycaemic attack at 1 am and subsequently complained of backache. A rather prominent mid-dorsal vertebral spinous process was noted. Radiography showed a compression fracture of T7.

Case 4-A man of 42 with an 11 year history of diabetes had been injecting insulin (Actrapid and Monotard) twice a day for seven years. One morning after his usual dose and before he had eaten his breakfast he became unconscious. He was found after five hours but despite treatment remained comatose for 24 hours. When he recovered he complained of pain in the mid-dorsal region and radiography showed compression of the bodies of $\mathrm{T} 4$ to $\mathrm{T} 7$.
1 Roberg OT. Spinal deformity following tetanus and its relation to juvenile kyphosis. Fournal of Bone and foint Surgery 1937;19:603-29.

2 Polantin P, Friedman MM, Harris MH, Horwitz WA. Vertebral fractures produced by Metrazolinduced convulsions. JAMA 1939;112:1684-7.

3 Worthing HJ, Kalinowsky LB. The question of vertebral fractures in convulsive therapy and in epilepsy. Am J Psychiatry 1942;98:533-7.

4 Vasconcelos D. Compression fractures of the vertebrae during major epileptic seizures. Epilepsia 1973;14:323-8.

(Accepted 7 August 1985)

The Middlesex Hospital, London W1N 8AA

J D N NABARRO, MD, FRCP, emeritus consultant physician 